\title{
The history of urea as a hyperosmolar agent to decrease brain swelling
}

\author{
Balint Otvos, Ph.D., ${ }^{1}$ Varun R. Kshettry, M.D., ${ }^{2}$ and Edward C. Benzel, M.D. ${ }^{2}$ \\ ${ }^{1}$ Cleveland Clinic Lerner College of Medicine; and ${ }^{2}$ Department of Neurosurgery, Neurological Institute, \\ Cleveland Clinic, Cleveland, Ohio
}

In 1919, it was observed that intravascular osmolar shifts could collapse the thecal sac and diminish the ability to withdraw CSF from the lumbar cistern. This led to the notion that hyperosmolar compounds could ameliorate brain swelling. Since then, various therapeutic interventions have been used for the reduction of intracranial pressure and brain volume.

Urea was first used as an osmotic agent for the reduction of brain volume in 1950. It was associated with greater efficacy and consistency than alternatives such as hyperosmolar glucose. Its use became the standard of clinical practice by 1957, in both the intensive care unit and operating room, to reduce intracranial pressure and brain bulk and was the first hyperosmolar compound to have widespread use. However, the prime of urea was rather short lived. Reports of side effects and complications associated with urea emerged. These included coagulopathy, hemoglobinuria, electrocardiography changes, tissue necrosis with extravasation, and a significant potential for rebound intracranial hypertension.

Mannitol was introduced in 1961 as a comparable and potentially superior alternative to urea. However, mannitol was initially purported to be less effective at rapidly reducing intracranial pressure. The debate over the two compounds continued for a decade until mannitol eventually replaced urea by the late 1960s and early 1970s as the hyperosmolar agent of choice due to the ease of preparation, chemical stability, and decreased side effect profile.

Although urea is not currently the standard of care today, its rise and eventual replacement by mannitol played a seminal role in both our understanding of cerebral edema and the establishment of strategies for its management. (http://thejns.org/doi/abs/10.3171/2014.1.FOCUS13558)

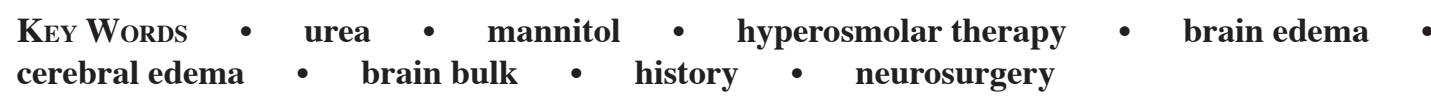

$\mathrm{T}$ HE regulation of intracranial pressure in the perioperative setting is critical to the success of any neurosurgical operation. Consequently, there has been much attention devoted to the management of intracranial pressure and brain volume. We now have a host of mechanisms by which we can alter these parameters. However, pharmacological compounds such as urea, mannitol, and hypertonic saline have only recently been used as therapy for reducing intracranial pressure. The hyperosmolar compounds initially trialed in the early 20th century for these purposes quickly fell out of favor, and use of these agents was not routine. Urea was the first hyperosmolar compound that could rapidly reduce cerebral pressure and the first to enjoy widespread use. The ubiquitous use of urea in neurosurgery was only realized for a brief time from the late 1950 s to the early 1970 s, but it was instrumental to our understanding behind the physiological mechanisms of how hyperosmolar compounds exert their effects and brought the use of hyperosmolar agents back to the forefront for the management of intracranial hypertension. Looking back at the rise to prominence of urea as the premier hyperosmolar compound and its eventual replacement by mannitol affords us an interesting historical perspective and one fundamental to shaping our management strategies to date. The history of urea allows one to understand the pharmacology of hyperosmolar therapies and provides blueprints for the development of the next generation of hyperosmolar compounds.

\section{History of Hyperosmolar Agents and the Discovery of Urea}

Osmolar therapy came into fruition in 1919 when Weed and McKibben discovered that intravenous hypertonic saline administration in cats resulted in a collapse of the lumbar cistern., ${ }^{7,56}$ In fact, their discovery was fortuitous since the original aim was to study CSF flow dynamics and electrolyte composition, as urged by Harvey Cushing. ${ }^{10}$ Cushing recognized the importance of a neurosurgeon's ability to understand and manage hydrocephalus. He stated "....much of the success of [the neurosurgeon's] intracranial and spinal work depends upon the ways and means he adopts to overcome the difficulties brought about by cerebrospinal fluid stasis, whether he is dealing with cerebrospinal anomalies, with tumors, with infections, or what not."10 At the time, little was known 


\section{B. Otvos, V. R. Kshettry, and E. C. Benzel}

about the etiology and treatment of hydrocephalus, although some basic concepts and techniques had come to light. In 1875, seminal work by Key and Retzius convincingly demonstrated that CSF was produced by the choroid plexus, flowed out of the ventricular system, and was resorbed through Pacchionian granulations. ${ }^{1}$ In 1881, Wernicke popularized ventricular puncture and external CSF drainage for therapeutic intervention. ${ }^{57}$ Quincke, building on previous work, in 1891 refined the lumbar puncture technique and demonstrated the ability to measure intrathecal pressure using a manometer. ${ }^{40}$ Subsequently, the first 2 decades of the 20th century saw the development of lumboperitoneal and ventriculoperitoneal drainage systems, as well as conduits to the subgaleal space, venous system, pleural space, and ureter. All, however, were associated with very high failure rates. , $^{13,19,20,30,37}$

Cushing recognized that the key to developing innovative treatments for hydrocephalus was to first better understand CSF physiology in the laboratory. As he stated, "Without more exact information on these matters than we now possess, it is fruitless to speculate upon the causation of these lesions, and past attempts to relieve them by operative measures have for the most part been made blindfold." 10 Cushing collaborated with Lewis H. Weed, and together they generated several important discoveries regarding our understanding of CSF physiology. Cushing provided evidence that CSF drained into the venous system, as digital occlusion of the internal jugular vein led to increased CSF accumulation..${ }^{9,53}$ Weed and Cushing further elucidated the mechanism of CSF absorption as primarily through filtration, rather than osmosis. ${ }^{54}$

In a subsequent experiment to their initial discovery regarding collapse of the lumbar cistern after hypertonic saline administration, Weed and McKibben found that intravenous $30 \%$ hypertonic saline resulted in a marked decrease in brain volume in cats, whereas injection of water resulted in significant brain swelling. ${ }^{55}$ Since the volume of both solutions was constant, they concluded that the change in brain bulk was due to osmolar shifts between the blood, brain, and CSF. Cushing took notice of these results, and was likely the first to identify the potential applicability of hyperosmolar solutions for reducing intracranial pressure and brain volume in the operating room..$^{14,41}$ These experiments were further confirmed in 1927 when Fremont-Smith and Forbes demonstrated that an intraperitoneal injection of hypertonic saline led to a reduction in CSF pressure in cats. ${ }^{3,15}$

These seminal experiments paved the way for further research with a variety of hyperosmolar compounds aimed at reducing intracranial pressure and brain volume. Compounds initially trialed included $50 \%$ glucose, $50 \%$ sucrose, $25 \%$ sodium chloride, $50 \%$ magnesium sulfate, concentrated albumin, and concentrated plasma, but all of these solutions were associated with a suboptimal reduction in CSF pressure, coupled with the propensity for intracranial rebound hypertension (known as the rebound phenomenon). ${ }^{32}$ Due to transient benefits and a significant side effect profile of the early hyperosmolar agents, their use fell out of favor in the 1930s, and the entire strategy for the management of brain swelling shifted away from hyperosmolar therapies. ${ }^{38,41}$ Although concentrated urea was used as a diuretic for other medical purposes, such as congestive heart failure, its potential applicability as a hyperosmolar agent was not realized for 3 decades. ${ }^{18}$ Upon its discovery, a host of experimental studies demonstrated the ability of urea to decrease intracranial pressure and brain volume..$^{29,48}$ One of the most promising initial assertions regarding urea was that it did not produce a rebound phenomenon, but this was eventually disproven in both experimental and clinical studies. ${ }^{42}$

In 1950, Smythe et al. demonstrated that urea was superior to hypertonic glucose or sucrose in reducing subarachnoid CSF pressure in monkeys.,47 Mann and Travaini showed that the intraperitoneal administration of urea in rats, using an epinephrine-induced postoperative cerebral edema model, led to a decrease in brain volume and histological cerebral edema compared with controls. ${ }^{31}$ Clasen et al. demonstrated the efficacy of urea in reducing brain volume and pressure in monkeys after inducing focal hemorrhagic necrosis. ${ }^{8}$ However, they noted that the administration of urea did not result in a reduction of brain edema in the pathological region. Spector demonstrated that the administration of hypertonic urea 24 hours after ischemic (carotid ligation) and anoxic (nitrogen inhalation) injury in rats reduced water within the brain and increased survival. ${ }^{8,48}$ Joyner and Freeman demonstrated a reduction in neurological disability following spinal cord injury in hypertonic urea-treated dogs. ${ }^{8}$ In 1954, Javid, Settlage, and colleagues first used hypertonic urea in clinical practice in the perioperative setting. By 1958, they had used hypertonic urea in 300 patients. ${ }^{24-27,41}$ Hypertonic urea rapidly became the standard of care to reduce intracranial pressure and brain volume in the 1960s and was the first hyperosmolar compound to enjoy widespread use. , $21,50^{2}$

\section{Mechanism of Action of Urea}

The use of urea to reduce intracranial pressure and brain volume, similar to other hyperosmolar agents, is predicated on the concept that water will passively diffuse from regions of lower osmolality to regions of higher osmolality in an effort to balance out the concentrations of osmoles. In the brain, extracellular water traverses into the intravascular space until osmotic and hydrostatic pressures are balanced, thereby temporarily reducing intracranial pressures by dehydrating the parenchyma. This osmotic gradient is transient and essentially determined by the extent to which the hyperosmolar compound remains in the intravascular space. This is determined primarily by two parameters. First, osmolar compounds harbor the tendency to diffuse from regions of higher to lower concentrations. As a result, the effectiveness of a hyperosmolar compound for reducing brain volume inversely correlates with the degree of penetration into brain tissue. Urea's penetration into brain tissue is onetenth the penetration into muscle, and its blood to brain transfer coefficient (a measurement of clearance) is $5 \times$ $10^{-3} \mathrm{ml} / \mathrm{g} / \mathrm{min}$, a value that is comparable to that of glycerol and 3 orders of magnitude lower than water., ${ }^{8,16,46}$ Second, urea undergoes renal excretion, further reducing the intravascular concentrations of the osmole. As a re- 
sult of these two equilibrating forces, imbalances in the osmolalities between the intravascular and extracellular spaces are short lived. After intravenous administration of urea, maximal parenchymal dehydration occurs 30 minutes after infusion and equilibriums return within 8 hours..$^{32,42,46}$

Initially, it was thought that diuresis was an important mechanism in the reduction of intracranial pressure. ${ }^{39}$ However, it was noted in surgery that a reduction in brain bulk occurred before an increase in urine output. Javid confirmed this observation in an experiment by demonstrating that intravenous urea administration in monkeys with bilateral nephrectomies led to an equivalent decrease in CSF pressure as controls. ${ }^{22}$

\section{Urea's Effect on Cerebral Physiology}

Although the basis of the mechanism of action of urea is straightforward, there are intricacies that are worth mentioning due to their potential clinical relevance. It was first assumed that the removal of water by urea from the brain parenchyma was from pathological regions with disrupted blood-brain barriers. However, controlled experiments in monkeys demonstrated that the transient reductions in pressure are primarily due to dehydration of normal cortex. ${ }^{8}$ The osmolar equilibration of urea in pathological regions is rapid due to leakage of urea molecules through a disrupted blood-brain barrier. Therefore, urea does not effectively prevent continued fluid accumulation in these regions. In fact, since extravascular urea is excreted more slowly than intravascular urea, a delayed gradient favoring water entry into brain tissue is generated. ${ }^{4,16}$ This can precipitate local rebound phenomenon.

Furthermore, the removal of brain water upon urea administration occurs almost exclusively from the gray matter. This occurs because swelling in the gray matter arises secondary to intracellular fluid accumulation, which can be withdrawn using osmolar agents, whereas swelling in the white matter arises secondary to extracellular compartmentalization of fluid. ${ }^{8,36}$ Finally, although brain parenchyma may be dehydrated, the overall levels of fluid within the intracranial cavity remain constant following urea infusion, due to compensatory increases in CSF and intravascular volumes. ${ }^{8,42}$ Subarachnoid CSF volume increases as the initial intracranial pressure drop leads to decreased absorption of CSF through arachnoid granulations. ${ }^{43}$ Total intracranial blood volume increases due to the osmotic transfer of water into pial vessels. ${ }^{44}$

\section{Clinical Experience}

Early case reports demonstrated that the administration of hypertonic urea reversed brain edema and alleviated neurological symptoms associated with overdialysis. ${ }^{11}$ In addition, in a small patient cohort, urea infusion normalized the alpha pattern of electroencephalography recordings of brains with cerebral edema. ${ }^{51}$ As previously mentioned, Javid and Javid and Settlage reported the largest clinical experience with the use of urea in neurosurgery and led the push for the widespread adoption of urea in clinical practice..$^{22,25,27}$ Stubbs and Pennybacker expanded on Javid's observations and suggestions outlining detailed urea administration protocols and potential side effects. ${ }^{50}$

Urea use was recommended when rapid reduction in intracranial or intraocular pressure was desired, both in cases of cytotoxic as well as vasogenic edema, with effects of a single administration lasting 4-8 hours ${ }^{50}$ (Fig. 1). Urea was also recommended on the 2 nd postoperative day to prevent brain swelling caused by parenchymal manipulation. ${ }^{50}$ Urea was also suggested after traumatic head injury, provided there were was no active bleeding and all hematomas were evacuated. ${ }^{50}$ Javid, in his experience of urea administration in more than 3200 patients, emphasized that the neurosurgeon must carefully control the timing and rate of urea administration during craniotomy. ${ }^{21,41}$ The urea infusion was initiated at the time of skin incision, except in large craniotomy flaps, in which he waited until the bone flap was removed to avoid epidural bleeding. However, he stated that one-half to twothirds of the infusion must be completed prior to dural opening to prevent cerebral herniation..$^{21,50}$ Urea quickly supplanted other hyperosmolar agents as the compound of choice where it enjoyed a reign of half a decade until the introduction of mannitol into the clinical arena (see The Rise of Mannitol).

\section{Limitations and Complications Associated With Urea}

After urea became widespread for the treatment of brain swelling, its limitations became more apparent. One of the concerns with urea was the difficulty associated with its preparation and administration. Urevert, 30\% urea with $10 \%$ invert sugar, ${ }^{22,50}$ was to be prepared within 24 hours prior to use. ${ }^{28,32}$ A cool environment was required, since heat exposure leads to degradation of urea. ${ }^{49}$ Therefore, special training for nursing staff was required to administer the agent, and stockpiles could not be made for use in emergencies. In addition, extravasation of nontrivial amounts of urea into the subcutaneous tissues due to infiltration of intravenous needles during administration led to skin necrosis and sloughing. ${ }^{21,22,28,39,45}$ Because urea is renally excreted, it was not recommended for use in individuals with renal impairment unless the patient was to receive dialysis. ${ }^{45}$ In addition, it was contraindicated in patients who were already dehydrated.7.32 Finally, due to the potential for platelet dysfunction, urea was contraindicated in patients with an intracranial hemorrhage prior to evacuation of the hematoma.,32

Urea was also found to be associated with several relevant side effects. Infusion of large quantities of urea led to nausea, vomiting, and diarrhea in awake patients. It also caused electrocardiographic rhythm changes such as ST elevation, T wave inversion, QRS distortion, and increased PR interval. ${ }^{6}$ These changes most likely occurred secondary to increases in intravascular potassium concentrations after urea administration, necessitating the slow infusion of urea. ${ }^{17}$ In addition, urea was associated with hemolysis, which resulted in hemoglobinuria. ${ }^{3,5,7,60}$ This occurred due to the facilitated diffusion of urea mol- 

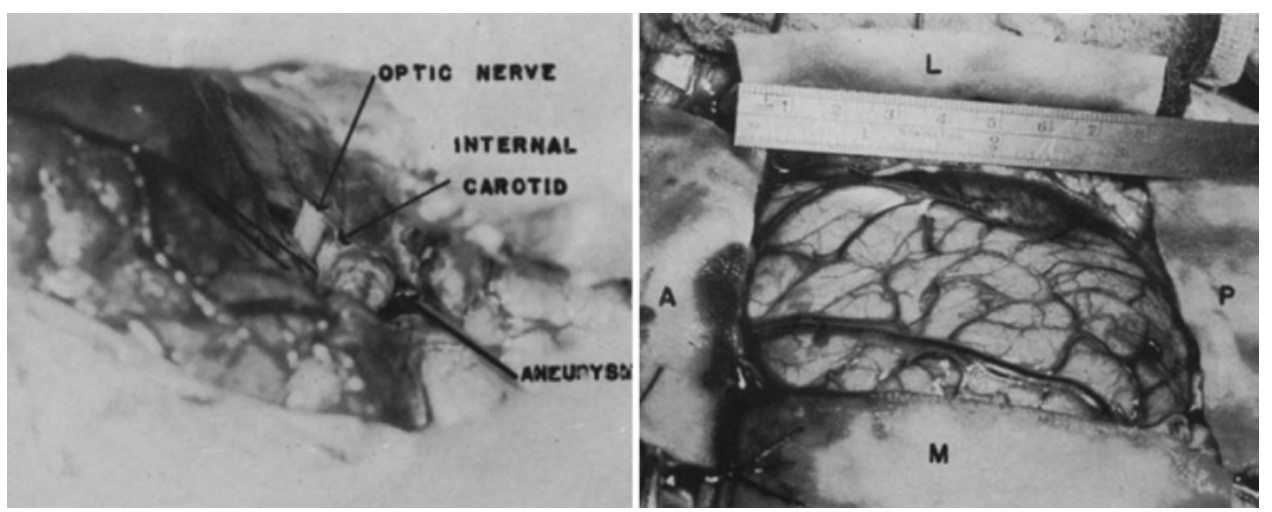

FIG. 1. Intravenous urea administration reduces intracranial edema. Left: Right frontotemporal craniotomy; $850 \mathrm{mg}$ urea/kg body weight was administered and a small amount of fluid was suctioned from the chiasmatic cistern allowing visualization of the right anterior cranial fossa, optic nerve, internal carotid artery, and aneurysm (with silk suture around neck prior to ligation) without the need for a retractor. Right: Photograph obtained during right temporal osteoplastic craniotomy (metastatic carcinoma). Shrinkage of the brain is illustrated following a dose of $1.6 \mathrm{~g}$ urea/ $\mathrm{kg}$ of body weight. Exposure of the lateral aspect of the middle fossa is maintained without the aid of a retractor. $A=$ anterior; $L=$ lateral; $M=$ medial; $P=$ posterior. Reprinted from Javid et al: $J$ Neurosurg 18:51-57, 1961, with permission.

ecules into erythrocytes with resulting entry of water and subsequent cell lysis. However, this side effect was somewhat mitigated by the mixture of urea with $10 \%$ invert sugar prior to administration. ${ }^{22,50}$

The two potential side effects with greatest neurosurgical implications were coagulopathy and rebound intracranial hypertension. The etiology of coagulopathy after urea administration was most commonly uremic platelet dysfunction. ${ }^{12}$ Neurosurgeons also noted that a rapid reduction in brain volume prior to craniotomy could result in troublesome epidural bleeding. ${ }^{50}$ This surgical complication was documented enough to warrant the suggestion that craniotomies should be completed prior to $50 \%$ of the urea infusion. ${ }^{21}$ However, perhaps most importantly, it was demonstrated that, contrary to initial reports and beliefs, urea could cause unpredictable rebound hypertension, ${ }^{32}$ a phenomenon that will be discussed in more detail in subsequent paragraphs.

\section{The Rise of Mannitol}

Mannitol's use as an alternative to urea was first described in 1961 by Wise and Chater as a nontoxic agent that was as equally effective as urea, but with a longer duration of effect. ${ }^{58,59}$ Mannitol is a larger molecule that, unlike urea, is not readily absorbed into tissues (Fig. 2). This would suggest that mannitol has a greater therapeutic effect due to less diffusion into the extracellular space. In addition, mannitol has a lower blood to brain transfer coefficient than urea, which many thought would result in a decreased incidence or severity of the rebound phenomenon. ${ }^{2,3,7,32,45}$ Mannitol could also be used more safely in patients with renal impairment. ${ }^{46}$ In addition, it is more easily prepared, is more stable once synthesized, and does not have the same side effect profile upon extravasation into subcutaneous tissues as urea. 7,32

Although it seems-based on the previous statements - that mannitol would have supplanted the use of urea rather rapidly once its utility had been realized, the debate between the use of the two compounds carried on for a decade. It was suggested in several studies that urea reduces intracranial pressure more rapidly than mannitol with lower dosing and that its rapid effect may be better suited for the perioperative or postoperative settings. ${ }^{2,3,17,28}$ Mannitol's limitations included greater diminution of plasma protein and hemoglobin values upon administration, and more potent diuresis, which precluded its use in
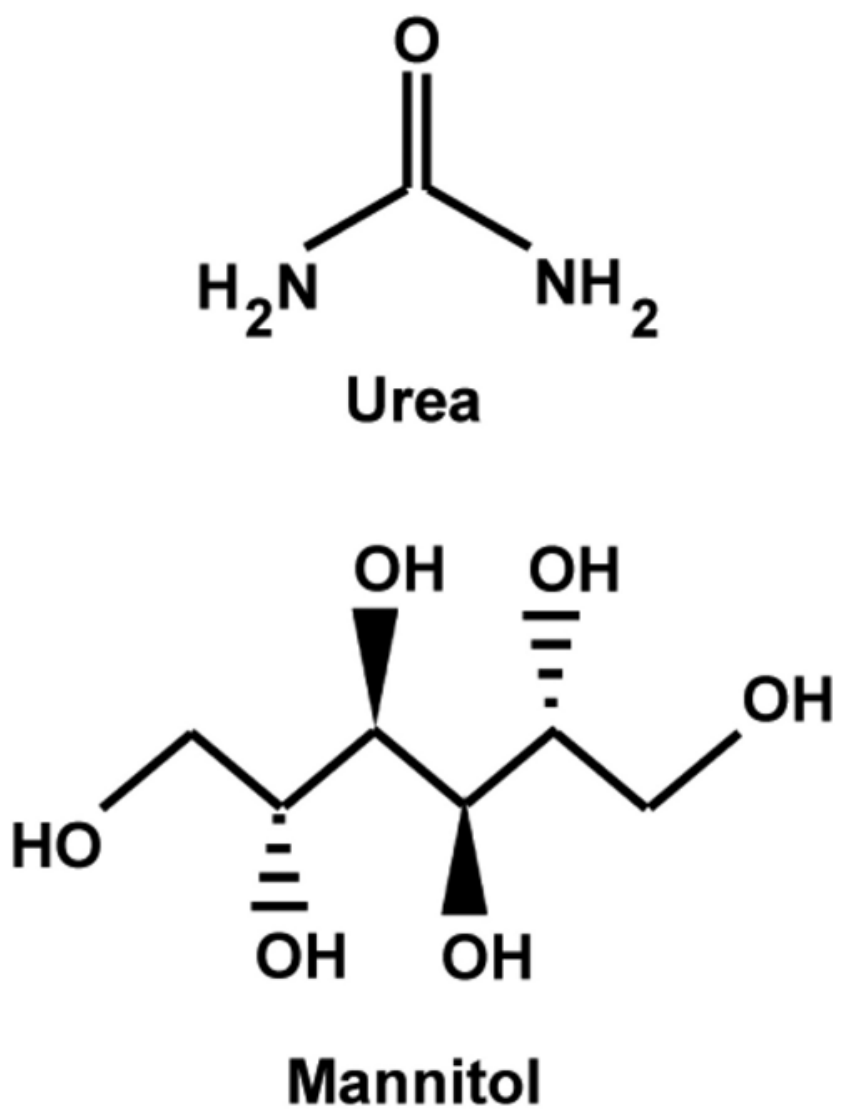

FIG. 2. Chemical structures of urea (upper) and mannitol (lower). 
volume-deficient patients. ${ }^{3}$ Furthermore, the initial comparisons between mannitol and urea with regard to their propensity for rebound hypertension were demonstrated to be somewhat inaccurate.

\section{The Rebound Phenomenon}

The greatest limiting factor for the use of any hyperosmolar compound is its potential to cause rebound hypertension due to normalization of fluids upon equilibration of osmoles in the various compartments (Fig. 3). Therefore, this complication deserves special attention in the debate. The reflection coefficient (a measure of permeability with 0 being completely permeable and 1 being impermeable) of urea is $0.44-0.59$ and mannitol is 0.9 in brain. ${ }^{39}$ These values indicate that, although mannitol is less permeable, it still crosses into the extravascular space and can have a propensity for a similar rebound phenomenon as urea. ${ }^{42,46}$ The previous theory was demonstrated in several independent studies, where mannitol was able to cause, albeit delayed in some cases, the same type of rebound phenomenon as urea with maximum rebound hypertension occurring 12-18 hours after administration of either compound. . $, 4,16,42$ It was also suggested that rebound phenomenon may occur due to a compensatory mechanism to maintain osmotic pressure of CSF above plasma and also as an effect of prolonged anesthesia. ${ }^{23,36}$ Nonetheless, when urea or mannitol was used clinically, rebound intracranial hypertension was a slow process. Therefore, neurosurgeons argued that while the phenomenon does exist, it generally was not frequent and severe enough to preclude the use of either compound. ${ }^{52}$

\section{The Replacement of Urea by Mannitol}

Although the use of urea continued for over a decade after the discovery of mannitol, it slowly fell out of favor. Claims regarding the propensity of urea to cause a more severe rebound phenomenon compared with mannitol were somewhat tempered, but the widespread thought was that urea was still more unpredictable than mannitol. ${ }^{7,32,34}$ Small case series in patients without intracranial pathology demonstrated that intraventricular pressure could potentially rise upward of $40 \%$ above baseline after urea infusion, lending further credence to those who were wary of the rebound phenomenon potential of urea. ${ }^{35}$ The complication profile of urea was also less favorable and mannitol was deemed less toxic and more readily excreted. Because the excretion of mannitol could be better controlled, the diuretic side effects of mannitol could be more tightly regulated. Concurrent to the rise of mannitol, steroid use to control cerebral edema was initiated, and this further limited urea's role in the management of intracranial hypertension. . 28,33 However, most importantly, the ease of preparation, chemical stability once synthesized, and reduced potential for complications during administration allowed mannitol to eventually overtake urea as the mainstream hyperosmolar agent of choice.?

\section{Conclusions}

Today, there are several mechanisms that are used to treat brain swelling in the perioperative room including, but not limited to, hyperosmolar agents such as mannitol. Unfortunately, we still do not have an ideal pharmacotherapy for the reduction of intracranial pressure and brain

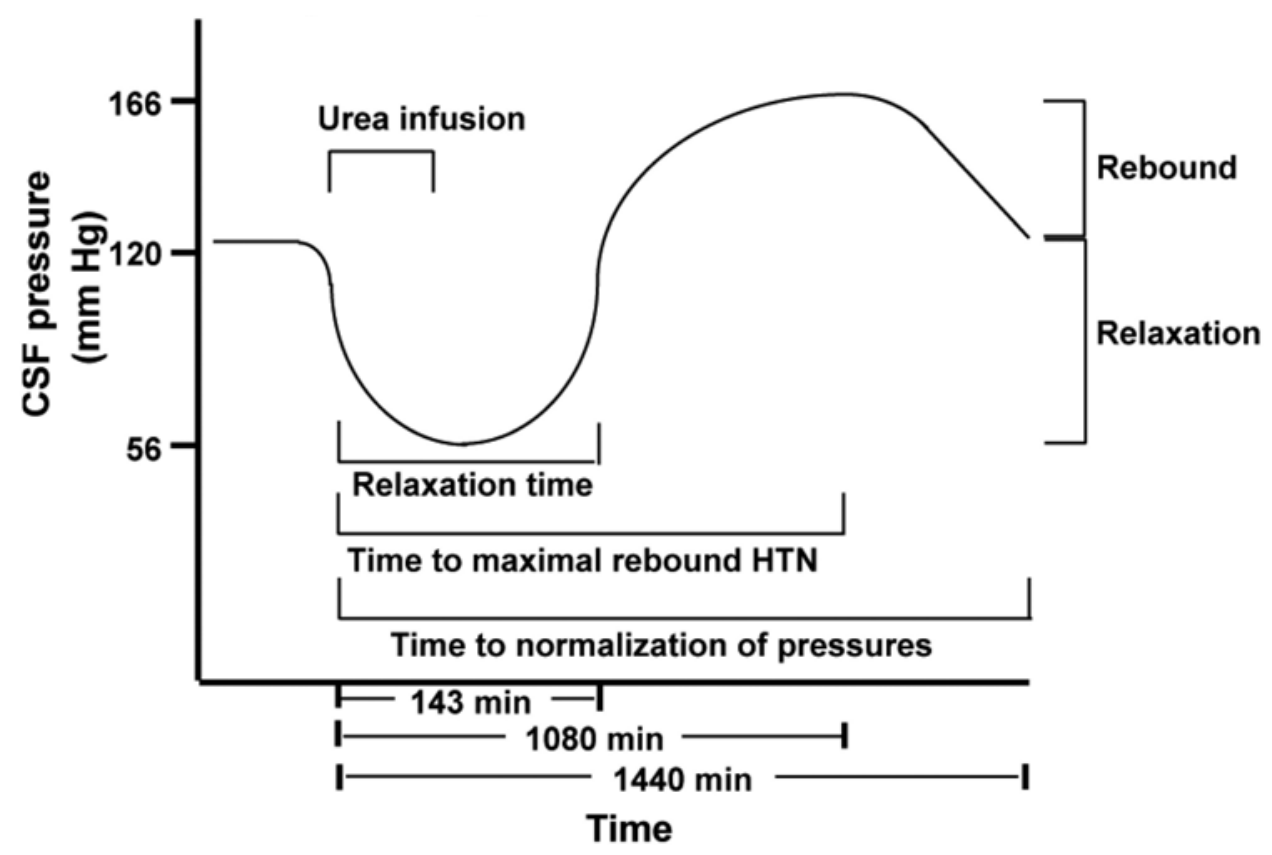

FIG. 3. Cerebrospinal fluid pressures after urea administration. Dogs were subjected to intravenous urea infusion and the subsequent CSF pressures were recorded. Brain relaxation was noted for 2.5 hours, maximal rebound hypertension was seen through 18 hours, and the pressures returned to equilibrium 24 hours after infusion. HTN = hypertension. Based on data from McQueen et al: J Neurosurg 21:118-128, 1964, and Rosomoff: Acta Anaesthesiol Scand Suppl 29:75-97, 1968. 


\section{B. Otvos, V. R. Kshettry, and E. C. Benzel}

volume. Urea was initially touted as a potential solution for the problem and brought the concept of hyperosmolar therapy into mainstream clinical practice but was demonstrated to have many of the same complications that had plagued previous therapies, as well as the therapies that are the standard of care today. However, elucidation of the mechanisms of action of urea and its comparison with other hyperosmolar agents paved the way for discoveries leading to a more complete understanding of the pathophysiology of cerebral edema and the hope of engineering new compounds to better combat this disease.

\section{Disclosure}

The authors report no conflict of interest concerning the materials or methods used in this study or the findings specified in this paper.

Author contributions to the study and manuscript preparation include the following. Conception and design: all authors Acquisition of data: Kshettry, Otvos. Analysis and interpretation of data: Kshettry, Otvos. Drafting the article: all authors. Critically revising the article: all authors. Reviewed submitted version of manuscript: all authors. Approved the final version of the manuscript on behalf of all authors: Kshettry. Study supervision: Benzel.

\section{References}

1. Aschoff A, Kremer P, Hashemi B, Kunze S: The scientific history of hydrocephalus and its treatment. Neurosurg Rev 22:67-95, 1999

2. Batzdorf U: The management of cerebral edema in pediatric practice. Pediatrics 58:78-87, 1976

3. Beks JW, ter Weeme CA: The influence of urea and mannitol on increased intraventricular pressure in cold-induced cerebral oedema. Acta Neurochir (Wien) 16:97-107, 1967

4. Beks JW, Walter WG: Some considerations on controlling cerebral oedema. Psychiatr Neurol Neurochir 71:9-12, 1968

5. Bensinger TA, Glader BE, Conrad ME: Intravascular hemolysis associated with intravenous urea infusions in normal individuals. Blood 41:461-464, 1973

6. Bering EA, Avman N: The use of hypertonic urea solutions in hypothermia: An experimental study. J Neurosurg 17:10731082,1960

7. Bhardwaj A: Osmotherapy in neurocritical care. Curr Neurol Neurosci Rep 7:513-521, 2007

8. Clasen RA, Cooke PM, Pandolfi S, Carnecki G, Bryar G: Hypertonic urea in experimental cerebral edema. Arch Neurol 12:424-434, 1965

9. Cushing H: Some experimental and clinical observations concerning states of increased intracranial tension. Am J Med Sci 124:375-400, 1902

10. Cushing H: Studies on the cerebro-spinal fluid: I. Introduction. J Med Res 31:1-19, 1914

11. Dossetor JB, Zborowski D: Mid-brain signs produced by hemodialysis and reversed by hypertonic urea. Can Med Assoc J 92:623-625, 1965

12. Escolar G, Díaz-Ricart M, Cases A: Uremic platelet dysfunction: past and present. Curr Hematol Rep 4:359-367, 2005

13. Ferguson A: Intraperitoneal diversion of the cerebrospinal fluid in cases of hydrocephalus. NY Med J 67:902-909, 1898

14. Foley FEB, Putnam TJ: The effect of salt ingestion on cerebrospinal fluid pressure and brain volume. Am J Physiol 53:464-476, 1920

15. Fremont-Smith F, Forbes HS: Intra-ocular and intracranial pressure: an experimental study. Arch Neurol Psychiatry 18:550-564, 1927

16. Go KG, van Woudenberg F, Woldring MG, Ebels EJ, Beks JW, Smeets EH: The penetration of $14 \mathrm{C}$-urea and $3 \mathrm{H}$-water into the rat brain with cold-induced cerebral oedema. Histological and autoradiographic study of the oedema. The effect of urovert. Acta Neurochir (Wien) 21:97-122, 1969

17. Goldstein SL, Himwich WA, Knapp FM, Rovine BW: Effects of urea and other dehydrating agents upon dog brain. J Neurosurg 21:672-677, 1964

18. Goodman LS, Gilman A: The Pharmacologic Basis of Therapeutics, ed 2. New York: MacMillan, 1955

19. Haynes IS: I. Congenital internal hydrocephalus: its treatment by drainage of the cisterna magna into the cranial sinuses. Ann Surg 57:449-484, 1913

20. Heile B: Über neue operative Wege zur Druckentlastung bei angeborenen Hydrocephalus (Ureter-Dura-Anastomose). Zentralbl Chir 52:2229-2236, 1925

21. Javid M: Urea in intracranial surgery. A new method. J Neurosurg 18:51-57, 1961

22. Javid M: Urea; new use of an old agent; reduction of intracranial and intraocular pressure. Surg Clin North Am 38:907-928, 1958

23. Javid M, Gilboe D, Cesario T: The rebound phenomenon and hypertonic solutions. J Neurosurg 21:1059-1066, 1964

24. Javid M, Settlage P: Clinical use of urea for reduction of intracranial pressure. Trans Am Neurol Assoc 82nd Meeting:151-153, 1957-1958

25. Javid M, Settlage P: Effect of urea on cerebrospinal fluid pressure in human subjects; preliminary report. J Am Med Assoc 160:943-949, 1956

26. Javid M, Settlage P: Use of hypertonic urea for the reduction of intracranial pressure. Trans Am Neurol Assoc 80th Meeting:204-206, 1955-1956

27. Javid M, Settlage P, Monfore T: Urea in the management of increased intracranial pressure. Surg Forum 7:528-532, 1957

28. Jones AG: Nursing implications in the administration of urea. J Neurosurg Nurs 7:37-41, 1975

29. Kaupp HA Jr, Lazarus RE, Wetzel N, Starzl TE: The role of cerebral edema in ischemic cerebral neuropathy after cardiac arrest in dogs and monkeys and its treatment with hypertonic urea. Surgery 48:404-410, 1960

30. Kausch W: Die behandlung des hydrocephalus der kleinen Kinder. Arch Clin Chir 87:709-796, 1908

31. Mann FD, Travaini DD: Experimental postoperative cerebral edema. J Neurosurg 20:687-691, 1963

32. Matson DD: Treatment of cerebral swelling. N Engl J Med 272:626-628, 1965

33. McClelland S III, Long DM: Genesis of the use of corticosteroids in the treatment and prevention of brain edema. Neurosurgery 62:965-968, 2008

34. McQueen JD, Jeanes LD: Dehydration and rehydration of the brain with hypertonic urea and mannitol. J Neurosurg 21:118-128, 1964

35. Nash FP, Orth G, Smolik EA: Intraventricular pressure after intravenous injection of urea. J Neurosurg 22:264-267, 1965

36. Pappius HM, Dayes LA: Hypertonic urea. Its effect on the distribution of water and electrolytes in normal and edematous brain tissues. Arch Neurol 13:395-402, 1965

37. Payr E: Drainage der Hirnventrikel mittels frei transplantierter Blutgefäße; Bemerkungen über Hydrocephalus. Arch Clin Chir 87:801-885, 1908

38. Penfield W: The principles of physiology involved in the management of increased intracranial pressure. Ann Surg 102:548-554, 1935

39. Pretorius JA: Intravenous urea (Urevert). A review. S Afr Med J 36:938-941, 1962

40. Quincke H: Die Lumbalpunktion des Hydrocephalus. Berlin Klin Wschr 28:929-933, 965-968, 1891

41. Rocque BG: Manucher Javid, urea, and the rise of osmotic therapy for intracranial pressure. Neurosurgery 70:1049-1054, 2012

42. Rosomoff HL: Cerebral edema and brain swelling. Acta Anaesthesiol Scand Suppl 29:75-97, 1968 


\section{Urea for brain swelling}

43. Rosomoff HL: Distribution of intracranial contents after hypertonic urea. J Neurosurg 19:859-864, 1962

44. Rosomoff HL: Effect of hypothermia and hypertonic urea on distribution of intracranial contents. J Neurosurg 18:753759,1961

45. Shields CB: Cerebral edema. Int Anesthesiol Clin 15:111123, 1977

46. Silver SM, Sterns RH, Halperin ML: Brain swelling after dialysis: old urea or new osmoles? Am J Kidney Dis 28:1-13, 1996

47. Smythe L, Smythe G, Settlage P: The effect of intravenous urea on cerebrospinal fluid pressure in monkeys. J Neuropathol Exp Neurol 9:438-442, 1950

48. Spector RG: Water content of the brain in anoxic-ischaemic encephalopathy in adult rats. Br J Exp Pathol 42:623-630, 1961

49. Streicher MH: Experimental uremia-uremic enteritis. Arch Intern Med 42:835-845, 1928

50. Stubbs J, Pennybacker J: Reduction of intracranial pressure with hypertonic urea. Lancet 1:1094-1097, 1960

51. Szabo L, Mathe A: The effect of urea and mannitol administration on the bioelectrical activity of the brain in cases of cerebral oedema. Rum Med Rev 43:35-40, 1963

52. Troupp H, Valtonen S, Vapalahti M: Intraventricular pressure after administration of dehydrating agents to severely braininjured patients: is there a rebound phenomenon? Acta Neurochir (Wien) 24:89-95, 1971

53. Weed LH: Studies on the cerebro-spinal fluid. No. II: The theories of drainage of cerebro-spinal fluid with an analysis of the methods of investigation. J Med Res 31:21-49, 1914
54. Weed LH: Studies on the cerebro-spinal fluid. No. III: The pathways of escape from the subarachnoid spaces with particular reference to the arachnoid villi. J Med Res 31:51-91, 1914

55. Weed LH, McKibben PS: Experimental alteration of brain bulk. Am J Physiol 48:531-558, 1919

56. Weed LH, McKibben PS: Pressure changes in cerebrospinal fluid following injections of solutions of various concentrations. Am J Physiol 48:512-530, 1919

57. Wernicke C: Lehrbuch der Gehirnkrankheiten für Aerzte und Studirende: Für Aerzte und Studirende. Berlin: Fischer Kassel, 1881

58. Wise BL, Chater N: Effect of mannitol on cerebrospinal fluid pressure. The actions of hypertonic mannitol solutions and of urea compared. Arch Neurol 4:200-202, 1961

59. Wise BL, Chater N: Use of hypertonic mannitol solutions to lower cerebrospinal fluid pressure and decrease brain bulk in man. Surg Forum 12:398-399, 1961

60. Wurster DE, Shapiro PH: Investigation of the mechanism of urea-induced hemolysis. J Pharm Sci 52:33-38, 1963

Manuscript submitted December 15, 2013.

Accepted January 20, 2014.

Please include this information when citing this paper: DOI: 10.3171/2014.1.FOCUS13558.

Address correspondence to: Varun R. Kshettry, M.D., Neurological Institute, S-40, Cleveland Clinic, 9500 Euclid Ave., Cleveland, OH 44195. email: kshettv@ccf.org. 